the group in which there is no change in the calcium and phosphate metabolism, in contradistinction to the more generalised or diffuse fibrocystic disease with multiple bone cysts, hyperparathyroidism, altered calcium and phosphorous values in the blood stream, the former raised, the latter lowered. In view of modern work on the " osteitis fibrosa" group it might be better perhaps to avoid the names of Paget and von Recklinghausen until with improved classification of bone diseases, they can be attached to definite types without adding to the confusion which even now exists.

\title{
ACUTE DACRYOADENITIS DUE TO THE MORAX-AXENFELD DIPLOBACILLUS
}

BY

\author{
LT.-COL. R. E. WRIGHT, C.I.E., I.M.S. and \\ RaO Bahadur DR. K. Koman Nayar \\ GOVERNMENT OPHTHALMIC HOSPITAL, MADRAS, INDIA
}

IN July, 1936, Dr. N. Pillai drew our attention to a run of three cases of acute dacryoadenitis which he had seen in the out-patient's department of this hospital within a few weeks and asked our opinion as to their nature. In two of them a few small subconjunctival beads of pus showed over the region of the accessory gland; otherwise they all subsided without suppuration. The condition is ordinarily very uncommon, and as the aetiology was in doubt it was determined to make cultivations from the enlarged preauricular gland of the third case on a variety of media which usually favour the growth of the conjunctival flora. The media were those found most satisfactory by Dr. B. P. B. Naidu, of the Medical Research Department of the Government of India, when investigating the normal and pathogenic conjunctival flora in this hospital in 1935-36 while collaborating in trachoma research.

Short clinical note.-The patient, a Hindu boy, aged 19 years, first felt pain at the right inner canthus on July 26, 1936, five days before admission. Next morning his upper lid was red, swollen and tender. $\mathrm{He}$ had photophobia and lacrymation, tenderness in front of the ear and slight fever. On coming to hospital, there was chemosis of the bulbar conjunctiva, swelling in the superior temporal quadrant of the orbit with pain and tenderness. The swelling projected into the conjunctival fornix in the superior temporal region, giving the impression of an acute adenitis of the whole gland. The accessory gland was visibly inflamed. The cornea was clear. There was no discharge. It is regrettable that smears and cultures were not made from the 
conjunctiva in any of the cases. The right preauricular gland was enlarged and tender. On admission, the temperature was normal, but rose to $100^{\circ}$ the following day, then fell to normal and did not rise again. He was treated by hot fomentations. On the third day-seventh day of disease-the preauricular gland was punctured with the usual precautions to avoid organismal contaminations. A needle on a syringe containing about half a cubic centimetre of broth was introduced, and the point of the needle moved about in the gland, slight positive and negative pressure being alternately exerted. The gland pulp thus obtained in broth was planted on blood agar, serum agar and Soparkar's medium (for composition see Indian Jl. of Med. Research, Vol. VI, page 418 ), and yielded in all a pure culture of the diplobacillus of Morax and Axenfeld.

This does not necessarily indicate that the other two cases were due to the same organism, and the reader may well wonder why the other cases were not investigated in the same way, or, why the preauricular gland was punctured rather than the lacrymal gland. The reason is that we did not take the aetiological problem seriously till the third case was well advanced. It occurred to us then, that there was a possibility of an epidemic of acute dacryoadenitis and by this time the preauricular gland was easier to deal with. It may be objected that even in the one case investigated it is not proven that the organism isolated from the preauricular gland was necessarily the aetiological agent of the dacryoadenitis. This is of course true and theoretically one might obtain such a common inhabitant of the conjunctiva as the MoraxAxenfeld bacillus, from an apparently normal preauricular gland, were it practicable to obtain gland pulp. There is however a reasonable probability that the cause of the dacryoadenitis in one case of the three-and possibly in all three cases-was the bacillus of Morax-Axenfeld.

\title{
ANGIOGLIOSIS RETINAE WITH REPORT OF TWO CASES
}

\author{
BY \\ IDA CZUKRÁSZ, M.D. \\ (FROM THE UNIVERSITY EYE CLINIC, DEBRECEN, UNDER THE \\ CHARGE OF PROFESSOR A. KREIKER)
}

v. Hippel first described angiogliosis retinae which is a part of the group-complex tumours of ectodermal origin found in the parenchymatous organs. In a fourth of the cases reported with cystic angiomas of the brain, spinal cord, tonsils, kidneys, pancreas, 